Revista Eletrônica do Mestrado em Educação Ambienta1

Programa de Pós-Graduação em Educação Ambienta1

\title{
O potencial encontro da Educação Ambiental com a Literatura de Cordel
}

\author{
Bruna Elizabeth Fraga de Araújo ${ }^{1}$ \\ Universidade Federal Rural do Rio de Janeiro- Instituto Multidisciplinar \\ https://orcid.org/0000-0001-6630-7716 \\ Fernanda Malheiro Lourenço ${ }^{2}$ \\ Universidade Federal Rural do Rio de Janeiro- Instituto Multidisciplinar \\ http://orcid.org/0000-0001-7077-5088 \\ Bárbara Pelacani ${ }^{3}$ \\ Universidade Federal do Rio de Janeiro \\ http://orcid.org/0000-0001-9349-0632
}

Resumo: O Cordel é uma expressão popular que aborda temáticas variadas, dentre elas a questão ambiental. O presente artigo visa apresentar a potência de se articular a Educação Ambiental (EA) aos Cordéis. O interesse na produção deste trabalho nasceu da importância de discutir sobre EA ao mesmo tempo pensando em práticas diferenciadas de intervenção. Este artigo foi construído a partir de uma revisão bibliográfica dos conceitos fundamentais da pesquisa: Literatura de Cordel e Educação Ambiental e uma posterior análise de cinco cordéis com o olhar da Educação Ambiental Crítica (EAC). Através deste trabalho pudemos observar como o cordel torna-se relevante para fundamentar uma EAC visto que é um material que traz à tona uma crítica a partir do território e ao mesmo tempo dialoga com os sujeitos oprimidos.

Palavras-chave: Literatura de Cordel; Educação Ambiental Crítica; Conhecimentos Tradicionais.

\section{El potencial encuentro de la educación ambiental con la Literatura del Cordel}

Resumen: Cordel es una expresión popular que aborda varios temas, entre ellos la cuestión ambiental. El presente artículo pretende presentar el poder de articular la Educación Ambiental

\footnotetext{
${ }^{1}$ Graduanda em Licenciatura Plena em Geografia. e-mail: brunaelizabethfraga19@ gmail.com

${ }^{2}$ Graduanda em Licenciatura Plena em Geografia. e-mail: fernandamalheiro8616@ gmail.com

${ }^{3}$ Doutoranda em Psicossociologia de comunidades e ecologia social, UFRJ Bióloga e Mestra em educação, UNIRIO. e-mail: barbara.pelacani@gmail.com

Rev. Eletrônica Mestr. Educ. Ambient. Rio Grande. v. 37, n. 1. Seção especial: XI EDEA - Encontro e Diálogos com a Educação Ambiental. p. 307-322. jan/abr. 2020. 
(EA) a los Cordeles. El interés por la producción de este trabajo nació de la importancia de discutir sobre EA al mismo tiempo que se pensaba en prácticas diferenciadas de intervención. Este artículo fue construido a partir de una revisión de la literatura sobre los conceptos fundamentales de la investigación: Literatura Cordel y Educación Ambiental y un posterior análisis de cinco cordeles con la mirada de la Educación Ambiental Critica (EAC). A través de este trabajo pudimos observar cómo la cadena se vuelve relevante para apoyar a una EAC, ya que es un material que suscita críticas desde el territorio y al mismo tiempo dialoga con los sujetos oprimidos.

Palabras clave: Literatura de Cordel; Educación Ambiental Crítica; Conocimientos Tradicionales.

\title{
The potential encounter of environmental education with Cordel Literature
}

\begin{abstract}
Cordel is a popular expression that approaches several themes, among them the environmental issue. The present article aims to present the power of articulating the Environmental Education (EE) to the Cordels. The interest in the production of this work was born from the importance of discussing about $\mathrm{EE}$ at the same time thinking about differentiated practices of intervention. This article was built from a literature review of the fundamental concepts of research: Cordel Literature and Environmental Education and a subsequent analysis of five strings with the look of Critical Environmental Education (CEE). Through this work we could observe how the string becomes relevant to support a CEE since it is a material that brings up criticism from the territory and at the same time dialogues with the oppressed subjects.
\end{abstract}

Keywords: Cordel Literature; Critical Environmental Education; Tradicional Knowledge.

\section{Introdução}

\author{
Além da inter-relação \\ Todo e qualquer ser vivente \\ Incluindo, claro, o homem \\ É eterno dependente \\ De todas as condições \\ Que formam o meio ambiente.
}

(SILVA, 2010, p. 7)

O campo da Educação Ambiental (EA) reconhece a literatura de cordel enquanto instrumento pedagógico e forma de aquisição de conhecimento, definindo a importância do olhar ambiental para a literatura popular, além do fortalecimento da socialização do conhecimento científico através da escrita popular (PEREIRA, et al. 2016; NOGUEIRA, 2016; QUEIROZ, 2012). Identificamos que alguns trabalhos estão voltados para educação formal, pensando sua aplicação enquanto instrumento pedagógico e também não formal.

Cordéis são destacados pelo papel relevante na conscientização individual e coletiva, sobre a necessidade do uso racional dos recursos naturais e da formação do cidadão planetário (QUEIROZ, 2012). O uso do cordel é caracterizado por agregar valor pedagógico e criativo, sendo fonte de resgate da cultura de raiz. Tais características podem

Rev. Eletrônica Mestr. Educ. Ambient. Rio Grande. v. 37, n. 1. Seção especial: XI EDEA - Encontro e Diálogos com a Educação Ambiental. p. 307-322. jan/abr. 2020. 
propiciar maior eficiência no processo de construção do conhecimento pelo educando (PEREIRA, 2016).

Os poetas cordelistas abordam a conscientização individual e coletiva como possibilidade de transformação socioambiental, trazendo também questionamentos econômicos e políticos (NOGUEIRA, 2016). Com isso, constatamos que a literatura popular é um ponto de interesse da EA, que vem sendo estudada por pesquisadores em diversas escalas acadêmica, indicando possíveis caminhos para se pensar uma Educação Ambiental Crítica (EAC) a partir da literatura popular.

Este trabalho visa apresentar a potência de se articular a Educação Ambiental aos Cordéis ao identificar as visões ambientais que aparecem permeadas nos versos; caracterizar o potencial educativo da abordagem crítica de temáticas socioambientais; além de buscar inspiração para uma educação ambiental que se propõe a dialogar com as comunidades nos territórios a partir das suas formas de produzir conhecimento.

O interesse na produção deste trabalho nasceu da importância de discutir sobre educação ambiental e ao mesmo tempo pensar práticas diferenciadas de intervenção, uma lacuna na educação ambiental crítica. Além de elaborar possibilidades de comunicação e aprendizagem através de materiais alternativos. Com a perspectiva crítica, conectada ao território e conhecimentos tradicionais, o uso do Cordel como expressão popular da questão ambiental é descrito no presente trabalho.

\section{Literatura de Cordel}

A Literatura de Cordel, conhecida também como folhetos ou romance, é uma poesia popular, com versos escritos na forma de rima e recitados de forma melodiosa. Tal gênero literário se origina em relatos orais e posteriormente impressos, muitas vezes de forma artesanal. Sendo uma expressão de manifestação do povo e um movimento de resistência cultural. Trata-se de uma manifestação típica do interior do Nordeste, impresso em folhetos rústicos, com ilustrações feitas com canivetes, estiletes (gravuras feitas com madeiras), e desenhos espontâneos e rústicos (xilogravuras).

O cordel foi assim denominado porque em Portugal era exposto em barbante para vendas em locais públicos. No Brasil, os cordelistas - poetas da Literatura de Cordel costumam vender suas produções em mercados e feiras, contribuindo para a difusão da arte folclórica nordestina.

Rev. Eletrônica Mestr. Educ. Ambient. Rio Grande. v. 37, n. 1. Seção especial: XI EDEA - Encontro e Diálogos com a Educação Ambiental. p. 307-322. jan/abr. 2020. 
Segundo Nemer (2011), o Cordel seria o sobrevivente moderno do romanceiro medieval. Em Portugal era conhecido como "Folhas Volantes", na Espanha como "Pliegos sueltos" e na França como "Litterature de Colportage". Começou a ser editado no século XVIII na Europa e lá circulou até meados do século XIX, quando começou a entrar em processo de desaparecimento.

Essa literatura chegou ao Brasil através dos impressos trazidos de Portugal pelos colonos. De acordo com o presidente da Academia Brasileira de Literatura de Cordel (ABLC), Gonçalo Ferreira da Silva, o Cordel chegou a Salvador, na mala dos colonizadores portugueses, e se irradiou pelos outros estados do Nordeste.

Segundo o site da ABLC (2019), a fundação da Academia ocorreu no dia 7 de setembro de 1988. A Diretoria foi composta por três cordelistas: o desde então presidente, Gonçalo Ferreira da Silva, o vice, Apolônio Alves dos Santos e o diretor cultural, Hélio Dutra. As primeiras reuniões dos três cordelistas aconteciam em uma sala cedida por um político. Após o vencimento do prazo de cessão da sala, as reuniões passaram a acontecer em bares, lanchonetes e restaurantes.

Após a conquista da sede própria, em 1990, o espaço tem servido para as reuniões de seus membros, exposição e consulta do acervo. Hoje, o corpo acadêmico da ABLC é composto de 40 cadeiras de membros efetivos, sendo que $25 \%$ destas cadeiras podem ser ocupadas por membros não radicados no Rio de Janeiro.

Em 2011, a Academia ganhou o Edital lançado pela Superintendência de Museus da Secretaria de Estado do Rio de Janeiro para "Modernização e Preservação de Museus e Centros de Memória”. Um ano depois, a ABLC foi reconhecida como Centro de Memória.

Até a última metade do século XIX o Cordel foi divulgado através da fala e do canto, "as narrativas que circulavam com muita popularidade na metrópole, foram transmitidas predominantemente pela fala - influência da herança africana, conhecida como akplô, que era partilhada entre os negros do Nordeste brasileiro" (NEMER, 2011, p. 22). Após esse período as histórias começaram a ser transmitidas em folhetos impressos.

Vale observar que de acordo com os cordelistas Fortaleza, et al. (2005), deve-se lutar para preservar a obra e o nome dos mestres do passado. Porém, as obras produzidas na atualidade devem conter elementos e características de seu tempo presente, que constituem o registro de sua época.

Rev. Eletrônica Mestr. Educ. Ambient. Rio Grande. v. 37, n. 1. Seção especial: XI EDEA - Encontro e Diálogos com a Educação Ambiental. p. 307-322. jan/abr. 2020. 
Está traçado o destino de quem teima em lutar contra o tempo, pois sempre sairá derrotado. Compete a nós conquistar sabedoria para pô-lo a nosso favor. Mesmo porque é obrigação do artista ser uma testemunha fidedigna de sua época e não de um passado que não viveu e não viverá jamais (FORTALEZA, et al., 2005, p. 15).

Os cordelistas argumentam também sobre a existência de alguns "pesquisadores" que insistem em ver o artista popular como "coitadinho", merecedor de toda a piedade e misericórdia.

Um injustiçado. Piedade, pena, misericórdia... O artista do povo não precisa de nada disso! Precisa, antes, de apoio, de espaço para se apresentar, para mostrar e comercializar sua produção, dignamente. Por este meio, mostrará toda sua capacidade criadora e contribuirá, sobremaneira, para o engrandecimento da sociedade na qual vive (FORTALEZA, et al., 2005, p. 16).

Por longo período, antes do aparecimento do rádio, o Cordel era o único meio de comunicação nas zonas rurais. Desde os princípios, seu sucesso não se deu apenas em virtude do menor preço, mas, também, pelo tom humorístico dado às histórias contadas e pela possibilidade de retratar personagens locais, como padre Cícero, Lampião, entre outros, além de fatos da vida cotidiana da cidade ou da região. Sendo um instrumento de memória social que trata de questões do território. Dentre estas, cabe destacar pelo interesse especial deste trabalho voltado para a reflexão da educação ambiental, questões sobre natureza, conflitos socioambientais e resistência que aparecem de forma específica em muitas publicações.

Um dos primeiros poetas que traz a questão ambiental em seus escritos é Alberto Porfírio de Quixadá - Ceará com o folheto "Não mate a natureza" (1979), onde aborda com características positivas a natureza, mas extrapola a visão conservadora ao trazer a censura quanto a atitude de hostilidade do ser humano em relação ao o mundo natural e abordar questões de classe ao responsabilizar os poderosos pela exploração dos mais pobres (NOGUEIRA, 2016).

Estes folhetos pedem ao leitor que reveja o seu conceito de "ser humano" e que contribua ativamente para uma mudança de paradigma cultural e ecológico. Mais voltados para a crítica dos abusos da humanidade sobre a natureza ou mais interessados em exaltar as belezas naturais, o princípio que lhes subjaz é o mesmo: é vendo-se como um ser na natureza que respeita tudo o que é não humano que cada pessoa pode alcançar uma consciência social e espiritual mais humana e integral. (NOGUEIRA, 2016. p.144)

Rev. Eletrônica Mestr. Educ. Ambient. Rio Grande. v. 37, n. 1. Seção especial: XI EDEA - Encontro e Diálogos com a Educação Ambiental. p. 307-322. jan/abr. 2020. 
O processo de resgate da literatura de cordel faz parte da tentativa de seu fortalecimento, principalmente no Nordeste nas últimas décadas. O cordel se posiciona como um meio de comunicação e difusão de informação. Para além de um simples meio de transmissão, identificamos seu potencial para o processo educativo, inclusive para o debate das questões socioambientais que aparecem entremeadas ao histórico do sertão.

\section{Educação Ambiental Crítica}

A EAC faz parte de um campo em disputa, onde pode se observar as diferentes formas em que a EA pode ser explicitada (LOUREIRO, 2007). Sendo assim, é importante entender as diferentes perspectivas. No sentido de facilitar este reconhecimento, Layargues e Lima (2014) abordam a EA sob três macrotendências: conservadora, pragmática e crítica. As duas primeiras não intencionam mudar as relações de poder e apontam a necessidade de mudanças em padrões comportamentais dos indivíduos. Já a crítica, segundo Loureiro (2007) e Guimarães (2004), está preocupada em desconstruir intencionalidades hegemônicas através da emancipação da sociedade buscando suprimir relações sociais de exploração e incentivar uma cidadania ativa.

Falar sobre EA atualmente é um desafio, visto que tal campo ao longo dos anos, desde o seu surgimento com a crise socioambiental do final do século XX, foi se desmembrando em categorias distintas, cada uma com suas especificidades e intencionalidades, envolvendo diversos atores. Representando diferentes perspectivas filosóficas, epistemológicas e políticas, que se atualizam junto com a conjuntura atual do país. Sobre isso Loureiro (2007) diz que:

Ao olharmos rapidamente para a história da educação ambiental, observamos que esta vem sendo adjetivada de várias formas. Isso se explica. O campo foi formado por diversas visões de mundo em diálogo e disputa, e nossa identidade se definiu mais pela negação ao estilo de vida urbano-industrial e aos valores culturais individualistas e consumistas do que por pontos comuns na proposição de alternativas. Com isso para não cairmos em uma visão homogeneizadora ou simplificada, acabamos por sentir a necessidade de explicitar as diferentes abordagens configuradas no modo de se fazer tal refutação e construir outros caminhos. (LOUREIRO, 2007, p. 67)

Rev. Eletrônica Mestr. Educ. Ambient. Rio Grande. v. 37, n. 1. Seção especial: XI EDEA - Encontro e Diálogos com a Educação Ambiental. p. 307-322. jan/abr. 2020. 
Com o processo de redemocratização do país, diversas mudanças políticas e sociais começaram a ocorrer, incluindo a EA, já que se organizaram vários movimentos sociais preocupados com a questão social e ambiental. Essa década também representou a instituição da educação popular de Paulo Freire que visava romper com o ensino tecnicista e depositário dos conhecimentos. Estes fatos e características foram incorporados pela EAC que se diferenciava da Conservadora e da Pragmática.

Segundo Guimarães (2004), a EA Conservadora parte da fragmentação da realidade e pauta a mudança individual como a responsável pela transformação da sociedade. Massoni (2019) complementa que esta reproduz as relações de poder existentes e não considera as condições sociais e históricas dos indivíduos.

Já a EA Pragmática, considerada uma derivação da anterior, busca a solução da crise socioambiental naqueles que seriam os causadores dessa crise. É uma educação que preza a transformação por meio de ações pontuais como coleta seletiva do lixo, consumo sustentável, a partir de um individualismo em que cada um que faça a sua parte. Uma visão ligada aos avanços da tecnologia, onde os meios serviram para resolver a crise. Uma perspectiva que muitas das vezes posicionam os mais atingidos pela crise socioambiental, como os causadores e culpados pelos problemas ambientais que os afetam diretamente.

Enquanto que a EAC, que também pode ser chamada de transformadora, popular, emancipatória e dialógica, visto que se origina de pressupostos democráticos, busca uma reflexão crítica e problematizadora das ações que levam as crises ambientais, não se esquecendo de incluir no debate "as ideias político-ideológicas do sistema de reprodução social e a inter-relação sociocultural do ser humano com a natureza". (SANTOS; TOSCHI, 2015, p. 247)

Conforme Carvalho (2004, p. 18) "o projeto político-pedagógico de uma EAC seria o de contribuir para uma mudança de valores e atitudes, contribuindo para a formação de um sujeito ecológico". Isto é, indivíduos e grupos sociais pensantes e atuantes sobre as questões socioambientais buscando a Justiça Ambiental. Compreendendo que indivíduo e coletividade precisam ser pensados juntos, já que é uma relação intrínseca destes na relação sociedade - natureza. Loureiro (2007) também acrescenta que:

Para a Educação Ambiental Crítica, a emancipação é a finalidade primeira e última de todo o processo educativo que visa a transformação de nosso modo de vida; a supressão das relações de expropriação,

Rev. Eletrônica Mestr. Educ. Ambient. Rio Grande. v. 37, n. 1. Seção especial: XI EDEA - Encontro e Diálogos com a Educação Ambiental. p. 307-322. jan/abr. 2020. E-ISSN 1517-1256 
dominação e preconceitos; a liberdade para conhecer e gerar cultura tornando-nos autônomos em nossas escolhas (LOUREIRO, 2007, p. 70).

Sendo assim é preciso superar as "armadilhas paradigmáticas" (Guimarães, 2004) e lutar contra a permanência de intencionalidades hegemônicas, no sentido de promover um processo educativo que incentive o exercício de uma cidadania ativa para a transformação da realidade socioambiental atual.

\section{Metodologia}

Este trabalho foi realizado a partir de duas ações, a primeira foi realizar uma revisão bibliográfica com o intuito de compreender melhor os conceitos fundamentais da pesquisa: literatura de cordel e educação ambiental. Através de uma revisão da literatura nas bases de dados científicos identificamos diversos trabalhos acadêmicos, inclusive dissertações de mestrado, que abordam a relação entre os temas, que nos apontaram para caminhos e lacunas. Para identificar a presença de temáticas ambientais nos cordéis nos utilizamos da metodologia de análise de conteúdo (BARDIN, 2011), diferenciando dentre as informações encontradas quais estão conectadas a uma EAC, pelo seu viés descrito no presente trabalho, buscando a potência do encontro da literatura popular com a visão crítica da EA.

Em seguida realizou-se uma análise dos cordéis escolhidos para a pesquisa. Foram observados cinco cordéis, dos quais três deles foram adquiridos na loja da Academia Brasileira de Literatura de Cordel, localizada no bairro de Santa Teresa (RJ), em um trabalho de campo realizado em junho do ano de 2019. E dois cordéis adquiridos em Aracaju (SE), no mercado municipal Antônio Franco, em setembro do mesmo ano.

\section{Análises e Resultados do Encontro da Educação Ambiental com os Cordéis}

Com base no referencial teórico-metodológico apresentado foram analisados os seguintes cordéis:

1. Águas Primordiais - Uma Viagem de 4,5 bilhões de anos - Gonçalo Ferreira da Silva, 2008.

2. As embalagens e os Impactos Ambientais - José Guilherme Teles, sem ano.

Rev. Eletrônica Mestr. Educ. Ambient. Rio Grande. v. 37, n. 1. Seção especial: XI EDEA - Encontro e Diálogos com a Educação Ambiental. p. 307-322. jan/abr. 2020. 
3. ECOLOGIA - Habitat - Laboratório onde a vida é produzida pela Natureza - Gonçalo Ferreira da Silva, 2008.

4. Não destrua a Natureza - Preserve o Meio Ambiente - João Firmino Cabral, sem ano.

5. Chico Mendes - O defensor da Floresta - Horácio Custódio de Souza, 2010.

Figura 1: Capas dos Cordéis analisados e verso com o Símbolo da Academia Brasileira de Literatura de Cordel

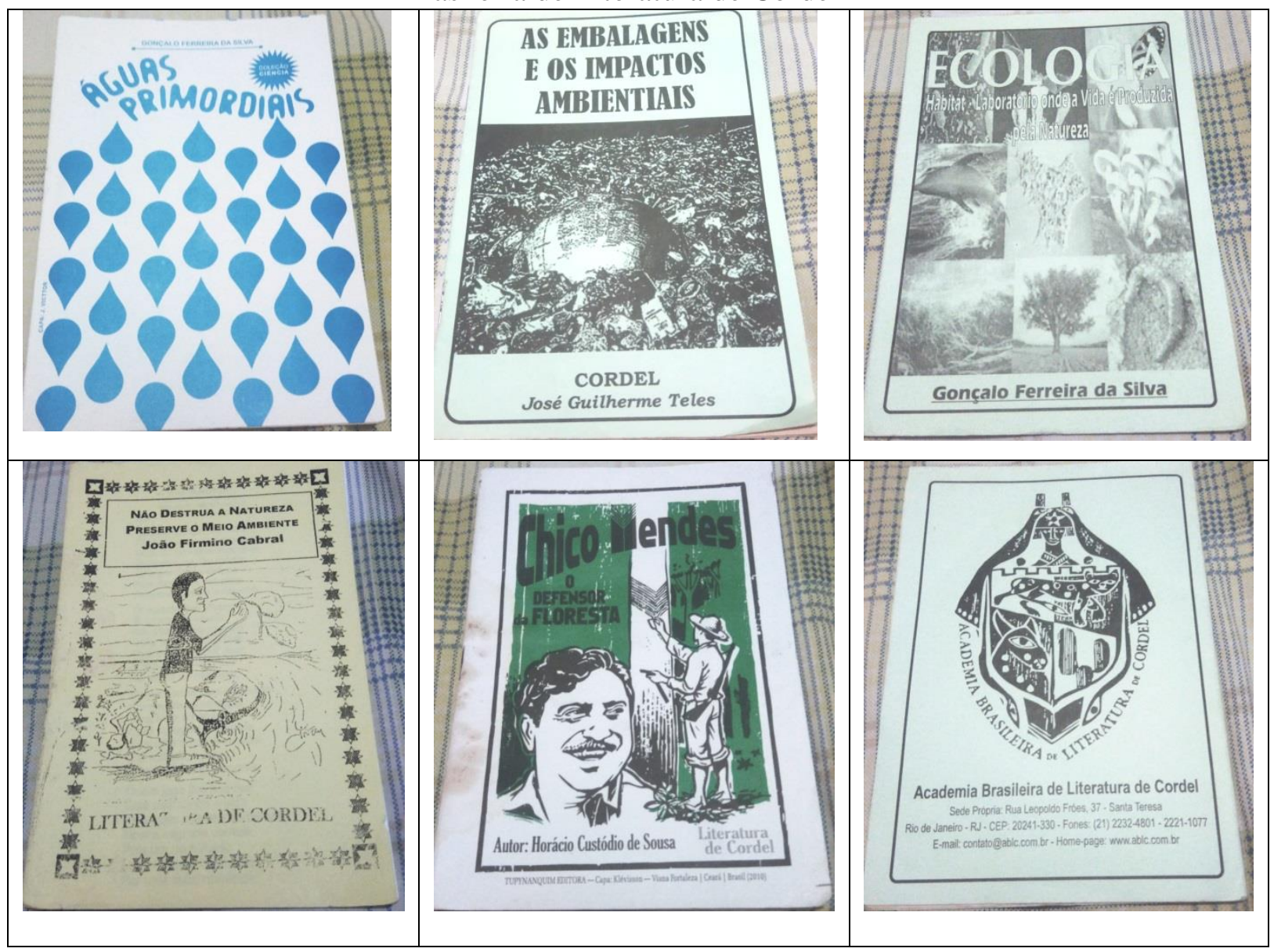

Fonte: Própria (2019)

O primeiro cordel, de autoria de Gonçalo Ferreira da Silva, intitulado “Águas Primordiais" (2008), trata da questão da água e sua importância não só para os ecossistemas, mas também para os seres vivos. Ele explicita a presença do elemento água desde a formação do planeta Terra, ressalta a importância de sua preservação, bem como aponta preocupação com as mudanças climáticas no território brasileiro, o que pode ser exemplificado no trecho a seguir:

Dezesseis por cento do / Território nacional A região nordestina / É o alvo principal

Rev. Eletrônica Mestr. Educ. Ambient. Rio Grande. v. 37, n. 1. Seção especial: XI EDEA - Encontro e Diálogos com a Educação Ambiental. p. 307-322. jan/abr. 2020. E-ISSN 1517-1256 
Pra se tornar vítima do / Aquecimento global (SILVA, 2008, p. 5).

Ao abordar especificamente o território de onde parte a literatura popular, este elemento conecta o escrito à EAC, ao romper com uma visão de um planeta único com uma população homogênea, onde os indivíduos são responsáveis de igual forma pelos impactos socioambientais. O autor também aponta como a água faz parte de nossas existências e que sem ela não há vida.

E como a água faz parte

Da quase totalidade / Do nosso corpo, sem ela

A grande e eterna verdade: / Não haveria biosfera,

E, portanto, humanidade (SILVA, 2008, p. 7).

Nesta passagem identificamos a presença do conceito de ambiente que engloba o ser humano enquanto ser constituinte, não existindo separação sociedade - natureza. Esta visão nos permite problematizar a ruptura que nos distancia das questões socioambientais, um ponto que atravessa a EAC.

Nas partes finais do cordel o autor enfatiza tal integração da sociedade com a natureza, pensando a Terra como ponto de partida para a vida e para as reflexões acerca das práticas realizadas que afetam a todos. O que inspira uma visão da coletividade para além de uma EA que propõe ações individuais.

A Terra, um grande teatro / Onde não há um vivente Que não esteja ligado / Ao outro, umbilicalmente E nesse palco da vida / A água é sua regente (SILVA, 2008, p. 8).

O segundo cordel, de autoria de José Guilherme Teles, intitulado "As embalagens e os Impactos Ambientais" (20--?), aponta como a forma de consumo atual é prejudicial tanto a sociedade como aos ecossistemas, explicitando a excessividade de lixo gerado e como isso contribui para a degradação e morte de seres vivos. É possível observar em diversos trechos ao longo do cordel, as críticas que o autor faz a essa problemática.

Ele vai superlotar, / Provocando explosões / Até populacionais, Os aterros e lixões, / Rapidamente lotados, Deixarão como legado / Doentes populações (TELES, [200-?], p. 2).

O folheto traz um conteúdo pedagógico crítico ao explicitar a ausência de preocupação do poder público com as populações que são atingidas.

Rev. Eletrônica Mestr. Educ. Ambient. Rio Grande. v. 37, n. 1. Seção especial: XI EDEA - Encontro e Diálogos com a Educação Ambiental. p. 307-322. jan/abr. 2020. 
As pessoas e animais / De modo descontrolado

Ingerem esses resíduos / Há muito contaminado /

Sofrem intoxicação, / Da vida degradação / Do poder desamparado (TELES, [200-?], p. 5).

O autor extrapola os limites territoriais nordestinos e traz o conflito que ocorre por conta dos resíduos para outras escalas, estendendo o debate local para o nível internacional.

Mas o assunto é mais amplo / Nível internacional,

No pacífico oceano, / Que lixão fenomenal!

Há um grande aglomerado / De entulho descartado

Lixão supranacional (TELES, [200-?], p. 2).

O terceiro cordel, também de autoria de Gonçalo Ferreira da Silva, intitulado "ECOLOGIA- Habitat- Laboratório onde a vida é produzida pela Natureza" (2010), trata de várias questões relacionadas aos ecossistemas. $\mathrm{O}$ autor pontua a relação de dependência dos seres com o ambiente. O mesmo versa sobre vários temas como o elemento água e suas formas em mares e rios, explicitando sua importância.

Os nossos rios são como / Um sistema arterial

Por onde passam suas águas / A riqueza natural

Do solo beneficia / A população local (SILVA, 2010, p. 12).

O autor fala da atmosfera, da flora e da fauna, ressaltando como o meio ambiente é rico em sua diversidade e como a vida conflui livremente seguindo o ritmo da natureza. Trazendo uma visão de abundância e de fertilidade enquanto riquezas do povo.

A vida flui livremente / No ambiente fecundo

E neste rico cenário / Nós povoamos o mundo

Onde o milagre da vida / Ocorre a cada segundo (SILVA, 2010, p. 18).

O quarto cordel, de autoria de João Firmino Cabral, intitulado "Não Destrua a Natureza - Preserve o Meio Ambiente" (20--?), trata da necessidade de preservar a natureza e suas obras para que os seres vivos possam sobreviver. $\mathrm{O}$ autor aponta várias ações que refletem essa luta, um exemplo é o incentivo a agricultura como forma de alimentação.

Devemos também criar / As condições para a vida

Fazer hortas a pomares / Plantar verdura em seguida

Pra nossa alimentação

Rev. Eletrônica Mestr. Educ. Ambient. Rio Grande. v. 37, n. 1. Seção especial: XI EDEA - Encontro e Diálogos com a Educação Ambiental. p. 307-322. jan/abr. 2020. 
Pois as hortaliças são / Vitamina garantida (CABRAL, [200-?], p. 3).

Cabral comenta sobre a importância do ser humano ser saudável para conseguir produzir suas condições de vida. A poluição, principalmente dos rios, é apontada por afetar a todos, espécies animais, vegetais e populações tradicionais.

\author{
O nosso rio Amazonas \\ Já sofre a poluição / dos esgotos das cidades \\ De quem não tem coração \\ Os peixes estão morrendo / E os pescadores sofrendo \\ Faltando a manutenção (CABRAL, [200-?], p. 5).
}

A importância da liberdade é expressa nesse cordel, uma categoria de extrema relevância para a educação ambiental. Pois defende o direito das populações poderem exercer suas práticas e descreve como isso é negado a partir do momento em que seus territórios são destruídos.

Nossos índios brasileiros / Amantes da liberdade Vivem hoje nas reservas / Ou morando na cidade Pra eles não têm mais festas / Pois dos rios e florestas Hoje só resta saudade (CABRAL, [200-?], p. 8).

O quinto e último cordel, de autoria de Horácio Custódio de Sousa, intitulado "Chico Mendes - O defensor da Floresta" (2010), narra a história do grande ecologista e seringueiro Chico Mendes e a luta dos nordestinos juntamente com os indígenas, contra a exploração e degradação da Floresta Amazônica. Um cordel que expõe a violência exercida sobre os povos da floresta a mando dos grandes fazendeiros e com aval do governo. Uma inspiração para pensar uma Educação Ambiental que se referencia nas lutas populares e na resistência comunitária.

Meu Deus que governo é esse / Que odeia o trabalhador?

Tomba um, justiça faz / Ouvido de mercador

Mas tombando um fazendeiro

Vem justiça com rigor (SOUSA, 2010, p. 5).

O autor aponta como os sujeitos, que detém o poder econômico cometem diversas injustiças socioambientais e seguem impunes. Denunciando que a justiça, que deveria ser imparcial, se faz de cega em muitas situações evidenciando relações de poder discrepantes.

Quem tem dinheiro querendo

Rev. Eletrônica Mestr. Educ. Ambient. Rio Grande. v. 37, n. 1. Seção especial: XI EDEA - Encontro e Diálogos com a Educação Ambiental. p. 307-322. jan/abr. 2020. 
Faz arbitrariedades

Desacata, rouba e mata

Com mil desonestidades

Que o dinheiro proíbe / De ficar atrás das grades (SOUSA, 2010, p. 6).

Sousa (2010) diz que é preciso desarticular essas redes de destruição e morte, pois o povo da floresta é parte integrante da natureza, e destaca sua harmonia com o meio. Neste trecho observamos uma potência para a educação ambiental, pois o autor identifica os sujeitos envolvidos nos conflitos socioambientais da Amazônia: os povos da floresta enquanto oprimidos pelo sistema hegemônico.

Desapropriar o índio / E o seringueiro da mata

É o mesmo que jorrar sangue / Da veia quando dilata

É destruir a virtude / Que a natureza acata (SOUSA, 2010, p. 25).

O mesmo finaliza ressaltando que a união da população consciente de seus direitos é capaz de transformar o país, o que nos aponta para uma vertente crítica da educação ambiental que pensa a transformação social.

Quando um povo consciente / Forma uma só união

Progride, constrói e cresce / Em forma de mutirão

Tem tudo para o avanço / De uma grande nação (SOUSA, 2010, p. 31).

O cordel de Sousa (2010) nos traz contribuições relevantes para finalizar tal análise, apontando para a atuação coletiva dos sujeitos, para a mobilização nacional, para busca por um outro mundo possível, em defesa da vida. O que nos inspira a pensar propostas pedagógicas outras, com referenciais teóricos e práticos populares, que brotam das comunidades, como é o caso dos cordéis.

\section{Considerações finais}

O Cordel é uma forma de comunicação que expressa a cultura popular nordestina, construída a partir da visão do território e com importante potencial pedagógico. Confirmou-se no presente trabalho a integração da Educação Ambiental com a Literatura de Cordel como um encontro que concretiza uma visão crítica. Com conteúdos populares e aterrizados nos saberes comunitários, a educação ambiental através dos cordéis tem a possibilidade de alcançar processos dialógicos com maior amplitude e profundidade.

Rev. Eletrônica Mestr. Educ. Ambient. Rio Grande. v. 37, n. 1. Seção especial: XI EDEA - Encontro e Diálogos com a Educação Ambiental. p. 307-322. jan/abr. 2020. 
A Literatura é capaz de criar novas visões de mundo e fazer emergir conceitos que são muito caros para a Educação Ambiental, que vem sendo re-trabalhados há décadas. O contexto social no qual tais materiais são produzidos é de extrema relevância, pois partem dos territórios, são contra-hegemônicos em sua maioria, o que aponta os Cordéis como uma estratégia para fundamentar a EAC.

Para além de um processo educativo socioambiental que incorpora a Literatura Popular enquanto instrumento pedagógico os cordéis têm o potencial de trazer a educação ambiental para o diálogo e de inspirar a atuação comunitária diante da crise socioambiental.

Os Cordéis incorporam elementos das diferentes perspectivas de EA aqui apresentadas, crítica, pragmática e conservadora. O que nos impulsiona a pensá-los enquanto material que sensibiliza, problematiza e propõe outras bases para a transformação social e autonomia dos territórios. Sendo assim, o potencial encontro que anunciamos se materializa neste trabalho ao caracterizarmos a literatura como conteúdo essencial para a Educação Ambiental, em especial para uma vertente crítica que germina dos sujeitos oprimidos.

\section{Referências}

ABLC. Academia Brasileira de Literatura de Cordel, 2019. História da ABLC.

Disponível em: http://www.ablc.com.br/a-ablc/historia/. Acesso em: 13 de out. de 2019.

BARDIN, Laurence. Análise de conteúdo. São Paulo: Edições 70, 2011.

CABRAL, João Firmino. Não destrua a Natureza, preserve o Meio Ambiente. [S.I]: [s.n], [200-?]

CARVALHO, Isabel. Cristina de Moura. Educação Ambiental Crítica: Nomes E Endereçamentos Da Educação. In: Identidades da Educação Ambiental Brasileira. Brasília: Ministério do Meio Ambiente, 2004.

FÔNSECA, Alexandre Vitor de Lima; FÔNSECA, Karen Sheron Bezerra. Contribuições da Literatura de Cordel para o ensino de Cartografia. Geografia - v. 17, n.2, jul/dez. 2008 - Universidade Estadual de Londrina. Departamento de Geociências . Disponível em: http://www.uel.br/revista/geografia. Acesso em 13 de out. de 2019.

FORTALEZA, Zé Maria; VIANA, Arievaldo; VIANA, Klévisson. A Didática Do Cordel. Ceará: Tupynanquim, 2005.

Rev. Eletrônica Mestr. Educ. Ambient. Rio Grande. v. 37, n. 1. Seção especial: XI EDEA - Encontro e Diálogos com a Educação Ambiental. p. 307-322. jan/abr. 2020. 
GUIMARÃES. Mauro. Educação Ambiental Crítica. In: LAYARGUES, P. P. (Org.). Identidades da Educação Ambiental Brasileira. Brasília: Ministério do Meio Ambiente, 2004.

LAYARGUES, Philippe Pomier.; LIMA, Gustavo Ferreira da Costa. As Macrotendências Político-Pedagógicas Da Educação Ambiental Brasileira. Revista Ambiente E Sociedade, v. XVII, n. 1, p. 23-40. São Paulo, 2014.

LOUREIRO, Carlos Frederico Bernardo. Educação ambiental crítica: contribuições e desafios. In: MELLO, Soraia; TRAJBER, Rachel. (Orgs.). Vamos cuidar do Brasil Conceitos E Práticas Em Educação Ambiental Na Escola. Brasília: Secretaria de Educação Continuada, Alfabetização e Diversidade (Secad) - Ministério da Educação, 2007.

MASSONI, Paolo de Castro Martins et al. Educação Ambiental Crítica, Da Teoria À Prática Escolar: Análise Da Experiência De Um Projeto No Contexto De Uma Escola Pública Do Rio De Janeiro. Revista Brasileira de Educação Ambiental, v. 14, n. 2, p. 86102. São Paulo, 2019.

MUSEUS DO RIO. Museus do Rio, 2019. Academia Brasileira de Literatura de Cordel. Disponível em:

http://www.museusdorio.com.br/joomla/index.php?\%20option=com k2\&view=item\&id=1 7:academia-brasileira-de-literatura-de-cordel\#sobre_o_museu . Acesso em: 13 de out. de 2019.

NEMER, Sylvia. Feira de São Cristóvão: a história de uma saudade. $1^{\circ} \mathrm{ed}$. Rio de Janeiro: Casa da Palavra, 2011.

NOGUEIRA, Carlos. Natureza e ambiente na literatura de cordel brasileira. Studies in Latin American Popular Culture 34, 128-146, 2016. Disponível em:

https://www.muse.jhu.edu/article/618711. Acesso em: 13 de out. de 2019.

PEREIRA, Gislaine Maria; SILVA, Amanda Celerino da.; SILVA, Paulo André da. De repente Cordel: processos avaliativos. In: CONGRESSO NACIONAL DE EDUCAÇÃO (CONEDU)., 3., 2016., Natal. Anais [...]. Campina Grande: Realize, 2016. Disponível em: https://editorarealize.com.br/revistas/conedu/trabalhos/trabalho ev056 md1 sa3 id 8622_17082016141938.pdf. Acesso em: 05 maio. 2018.

QUEIROZ, Paulo Márcio Santos de. Cordel: um instrumento para a educação ambiental. 2012. 111 f. Dissertação (Mestrado em Planejamento Ambiental) Universidade Católica de Salvador, Salvador, 2012.

SANTOS, Jéssica de Andrade; TOSCHI, Mirza Seabra. Vertentes da Educação Ambiental: da conservacionista à crítica. Revista Fronteiras, v. 4, n. 2, p. 241-250. 2015.

SILVA, Gonçalo Ferreira da. Folhetos de Cordel traziam diversão e informação ao povo nordestino. [ Entrevista concedida a] portal G1. Portal G1, http://g1.globo.com/economia/agronegocios/vida-rural/noticia/2012/01/folhetos-de-cordeltraziam-diversao-e-informacao-para-o-povo-nordestino.html. Atualizado em 16/01/2012

Rev. Eletrônica Mestr. Educ. Ambient. Rio Grande. v. 37, n. 1. Seção especial: XI EDEA - Encontro e Diálogos com a Educação Ambiental. p. 307-322. jan/abr. 2020. 
SILVA, Gonçalo Ferreira. Águas Primordiais. [S.I]: [s.n], [2008]

SILVA, Gonçalo Ferreira. ECOLOGIA: Habitat - Laboratório onde a vida é produzida pela natureza. [S.I]: [s.n], [2010]

SOUSA, Horácio Custódio. Chico Mendes O Defensor da Floresta. [S.I]: [s.n], [2010]

TELES, José Guilherme. As Embalagens E Os Impactos Ambientais. [S.I]: [s.n], [200-?]

Submetido em: 24-01-2020.

Publicado em: 17-04-2020

Rev. Eletrônica Mestr. Educ. Ambient. Rio Grande. v. 37, n. 1. Seção especial: XI EDEA - Encontro e Diálogos com a Educação Ambiental. p. 307-322. jan/abr. 2020. 